\title{
DESENVOLVIMENTO E ARTE CONCRETA NO BRASIL
}

\author{
Maria Lúcia Kern
}

\section{INTRODUÇÃO}

Durante a $2^{a}$ guerra mundial, o Brasil passa por um rápido e grande crescimento econômico, provocado pela política desenvolvimentista nacional de Getúlio Vargas e pela substituição das importações, mediante o incentivo à produção industrial nos setores de bens de consumo não duráveis e de bens intermediários. Esta política e ideologia desenvolvimentista tem continuidade após a queda do Estado Novo, quando o regime político ditatorial é substituído por um regime de feição liberal democrática e de tendências populista e autoritária.

A ideologia desenvolvimentista consiste em "superar o Brasil periférico, arcaico, ignaro e superticioso (...) O que não tem função morra e pereça!... não é outro o sentido do novo progressismo, vestido agora à americana, e forrado de palavras de ordem: pela indusirialização, pela urbanização, pela tecnologia; e logo: pelo controle racional de todos os níveis"1.

Há uma grande preocupação em superar o subdesenvolvimento e em modernizar a sociedade brasileira através de um planejamento objetivo nacional, bem como em divulgar a "ideologia imagética" (segundo conceito de Nicos Hadjihicolaou) em voga nos países desenvolvidos. O processo de industrialização ocorre principalmente no centro e no sul do país, sendo São Paulo o Estado que mais cresce.

Nos anos 50, São Paulo torna-se também o centro artístico do país, graças à criação de novos museus e bienais. Esta iniciativa deve-se à burguesia que se afirma através da ideologia desenvolvimentista e que busca expressar a modernidade e o progresso econômico do país também por meio das artes plásticas.

Em 1947, Assis Chateaubriand, diretor dos Diários Associados, cria o Museu de Arte de São Paulo - MASP. No ano 
seguinte, Francisco Matarazzo Sobrinho, funda o Museu de Arte Moderna - MAM - e, em 1951, a Bienal de São Paulo que possibilita o conhecimento e o contato dos artistas brasileiros com as vanguardas européia e americana.

No Rio de Janeiro, um grupo de empresários, intelectuais e políticos, no qual se destaca Raimundo de Castro Maya, grande industrial e colecionador de arte, toma a iniciativa de criar o Museu de Arte Moderna - (MAM) - em 19492. Este é estruturado segundo o MAM de Nova York.

A elite brasileira procura também acompanhar as inovações das grandes cidades da Europa, como Paris e Roma, que tiveram seus museus de arte moderna criados no após $2^{\mathrm{q}}$ guerra mundial.

Os novos museus do país têm a sua forma de organização e de manifestações baseada nas instituições européias e americanas, bem como nas concepções recentes de museologia.

Estes museu caracterizam-se por ser dinâmicos, visto que promovem exposições temporárias, trazendo obras de outras instituições ou de coleções particulares e motivando, assim, o público a visitá-los seguidamente. Organizam também cursos de artes plásticas, tornando-se verdadeiros laboratórios de produção artística.

Os novos museus são frutos da ideologia desenvolvimentista, dominante no meio das elites brasileiras, que buscam atualizar a arte e suas instituições. Segundo Mario Barata, a tarefa mais séria dos museus é de não esquecer as conquistas seguras do modernismo e expor a diversidade da produção artística contemporânea ${ }^{3}$.

Com o crescimento econômico brasileiro e o estreitamento das relações comerciais internacionais, a elite entra em contato com as produções artísticas dos países desenvolvidos. Esta, desejosa da participação do Brasil nas manifestações internacionais, promove nos museus exposições de artistas de vanguarda da Europa e dos EUA, bem como consegue que os nossos artistas participem da Bienal de Veneza, em 1950.

É a partir desta Bienal, e segundo o seu modelo, que Francisco Mattarazzo Sobrinho tem a idéia de criar a Bienal de São Paulo, a qual é organizada inicialmente pelo MAM. Com 
as bienais e as promoções dos novos museus, a arte no Brasil sofre um processo de "internacionalização", acompanhando assim os movimentos das vanguardas européia e americana.

Portanto, após a $2^{a}$ guerra mundial, a elite dominante brasileira atua como estimuladora das artes plásticas, criando instituições e promovendo manifestações, que são dirigidas para a representação de sua própria ideologia em forma de imagem. Esta, por sua vez, é um prolongamento da arte e da ideologia das elites dirigentes dos países desenvolvidos, as quais têm interesse em manter a dependência cultural do mesmo modo que a econômica.

\section{A difusão da nova arte}

Através dos museus e bienais a elite brasileira incentiva a introdução e a difusão das artes concreta e abstrata, em voga nos países desenvolvidos, no eixo Rio de Janeiro/São Paulo.

Inicialmente, são promovidas exposições de arte das vanguardas euro-americanas, nas quais muitos dos objetos apresentados fazem parte de coleções particulares da elite. Com a finalidade de realizar mostras bem atualizadas em relação à arte contemporânea internacional, o MAMSP faz um convênio com o MAM de Nova York.

Mais tarde, as novas instituições de arte começam a organizar cursos e exposições de trabalhos concretos e abstratos de artistas brasileiros 4 .

Deve-se salientar que o papel da crítica é bastante significativo, visto que esta atua não somente como defensora e difusora da nova arte, mas também como teórica dos grupos e dos movimentos que surgem paulatinamente.

Em 1949, por exemplo, quando é realizada a 1ạ exposição do MAM de São Paulo, "Do figurativismo ao abstracionismo", Francisco Matarazzo Sobrinho empresta parte do seu acervo e Léon Degand, crítico francês e diretor deste museu, faz uma análise da figuração e da abstração no catálogo. Nesta análise Degand destaca a diferença entre os dois tipos de arte e os aspectos positivos da abstração. "As cores e tonalidades de uma pintura abstrata, uma vez que não são reunidas pelo pintor e nem consideradas pelo expectador em função de qualquer 
relação de imitação com o mundo exterior, são susceptíveis de combinações expressivas que a pintura figurativa por definição não pode conhecer."

Degand esquece que a figuração moderna utiliza cores arbitrárias que não têm relação com o mundo exterior, porque o artista não está preocupado em "reproduzir o visível, mas em torná-lo visível"5.

Degand, quando se refere à figuração, tem como parâmetro o sistema de representação acadêmico. Esquece que na pintura moderna esta figuração constitui um sistema diferente e mais flexível. Mas o objetivo principal do crítico parece ser o de mostrar as qualidades e a importância da abstração, apelando, assim, para generalizações inaceitáveis.

O crítico Mário Pedrosa desempenha também um papel significativo para a difusão da abstração, quando defende, em 1948, uma tese "Da natureza afetiva da forma na obra de arte", na Faculdade de Arquitetura do Rio de Janeiro. É a primeira tese no Brasil em que a arte é analisada segundo a "psicologia da forma" (Gestalt), sendo estudada assim por alguns artistas, como Almir Mavignier e Ivan Serpa, que logo começam a praticar as primeiras experiências não-figurativas, e a se preocupar mais com o aspecto formal do objeto artístico.

Waldemar Cordeiro e Ferreira Gullar, críticos de arte, atuam como teóricos dos movimentos concreto e neoconcreto, em São Paulo e no Rio de Janeiro, respectivamente.

Alguns artistas, como Mavignier, Serpa e Palatnik, procuram entrar em contato com representantes do concretismo argentino que seguem a orientação dos mestres europeus; outros, como Mary Vieira e Mavignier, vão à Europa para estudar diretamente com os grandes mestres da arte concreta.

O mercado de arte começa a assumir uma estrutura mais complexa, com a criação de galerias de arte, a partir de 1945.

Os museus com suas exposições e aquisições de vanguar$\mathrm{da}$, e as bienais com as premiações para objetos de vanguarda, institucionalizam a nova produção artística, juntamente com a crítica e incentivam, deste modo, a comercialização e a difusão desta. 


\section{O croncretismo e a ideologia desenvolvimentista}

As artes concreta e abstrata penetram rapidamente no país, graças à ideologia desenvolvimentista que é abraçada por grande parte da elite brasileira. Estas expressam o ideal progressista e modernista

O concretismo afirma-se como arte que nega a representação da imagem-idéia e se fixa apenas na imagem-forma, isto é, no caráter formal puro do objeto. É extremamente objetivo e racional, chegando a fazer uso da matemática para a construção do objeto. Utiliza-se muitas vezes de novos materiais e técnicas, como o eucatex no lugar da tela, o esmalte substituindo a tinta a óleo, a pistola sobrepujando o pincel...

Tanto na pintura, como na escultura são introduzidos novos materiais e tecnologia, que simbolizam o progresso técnico e o racionalismo que deveria dominar a cultura e a arte da sociedade moderna brasileira.

A pintura concreta, segundo Waldemar Cordeiro, um dos autores do manifesto Ruptura (concreto), baseia-se em princípios diversos da pintura executada até o momento no país. Ela é construída num espaço bidimensional (e não tridimensional), apresentando, assim, formas planas que se caracterizam pela atonalidade e pelo movimento linear (fatores de proximidade e de semelhanças que possibilitam uma espécie de vibração ótica6. Na pintura tridimensional, ao contrário, as figuras são volumosas, sendo constituídas por tonalidades, jogos de luz e sombra e por possíveis movimentos.

O concretismo na arquitetura, pintura e poesia difunde-se mais em São Paulo - centro industrial e econômico - do que no Rio de Janeiro. Na primeira cidade, os artistas concretos buscam a aplicação profissional da arte no desenho arquitetônico, no desenho industrial, na publicidade... Waldemar Cordeiro, teórico do movimento, no manifesto "O Objeto", deixa clara a mudança de concepção de arte, quando afirma que esta não é mais expressão, mas produto. Defende o conceito de arte produtiva, rompendo desta forma com o idealismo e emancipando a "arte da condição secundária e dependente a que tinha sido relegada."7

A arte concreta é mais praticada por arquitetos, estudantes de arquitetura e mesmo engenheiros do que por artistas plás- 
ticos, não só pelo seu caráter utilitário, mas principalmente pelos princípios rígidos e objetivos que a regem.

Durante a presidência de Juscelino Kubiłschek, a ideologia desenvolvimentista domina a sua orientação política e a arte concreta, bem como o construtivismo, símbolos dessa, atingem o apogeu com a construção de Brasília. A nova capital, como afirmou Juscelino, "nasceu sob o signo da arte" e representa a síntese das artes, o pragmatismo e o racionalismo arquitetônicos.

Em 1959, no Rio de Janeiro, um grupo de artistas Frente - rompe com a arte concreta, através do manifesto neoconcreto.

Neste manifesto, Ferreira Gullar - teórico e poeta neoconcreto - afirma que esta expressão indica a oposição face à arte não-figurativa geométrica e, especialmente, face à "arte concreta levada a uma perigosa exacerbação racionalista".

Ferreira Gullar não aceita o caráter rígido e mecanicista da arte concreta, bem como a estreita relação que esta mantém com a ciência. Para ele, a obra de arte "começa a interessar precisamente pelo que nela há (...) pelo universo de significações existenciais que ela a um tempo funda e revela". O manifesto rompe, deste modo, com o princípio de que a obra deve constituir apenas imagem-forma.

O teórico do neoconcretismo critica a visão de que o homem é "uma máquina entre máquinas" e que a arte deve ser uma expressão da realidade teórico-moderna8.

Não é plausível, também, a difusão da arte concreta num país dependente como o Brasil dos anos 50, cuja tecnologia é importada e cuja ciência é insignificante.

A arte concreta não é uma criação espontânea do artista brasileiro. Ela é transplantada de um país desenvolvido Suíça - para a sociedade brasileira, que passa por um processo de industrialização, mas sem a sofisticada tecnologia européia.

A adoção do concretismo no Brasil visa simbolizar o seu nível de desenvolvimento artístico em relação à Europa e aos Estados Unidos, bem como a racionalidade e a objetividade de 
pensamento e de cultura que a elite gostaria que se tornasse comum no pais.

A negação do concretismo significa a negação desta ideologia da racionalidade bastante difundida no meio intelectual e artístico do eixo Rio de Janeiro/São Paulo. Significa ainda a produção de uma arte mais próxima à realidade brasileira e a negação do falso.

A difusão do abstracionismo, quase na mesma época que o concretismo, representa também a não aceitação de uma arte excessivamente racional e objetiva.

Mas o abstracionismo, como quase toda arte erudita, não deixa de expresar a ideologia da elite dominante, na medida que esse é uma forma de arte modernista e que representa a atualização artística e cultural, assim como o progresso econômico do país.

A abstração apresenta especificidades, quando transplantada para o Bŕrasil, merecendo, deste modo, um estudo maior.

Tanto o concretismo, como o abstracionismo são artes contemporâneas internacionais. Ao serem absorvidos e difundidos nos principais centros brasileiros exprimem a ideologia desenvolvimentista, se bem que adotem aspectos diversos da mesma.

Pontifícia Universidade Católica do Rio Grande do Sul Departamento de História

Porto Alegre - Brasil 


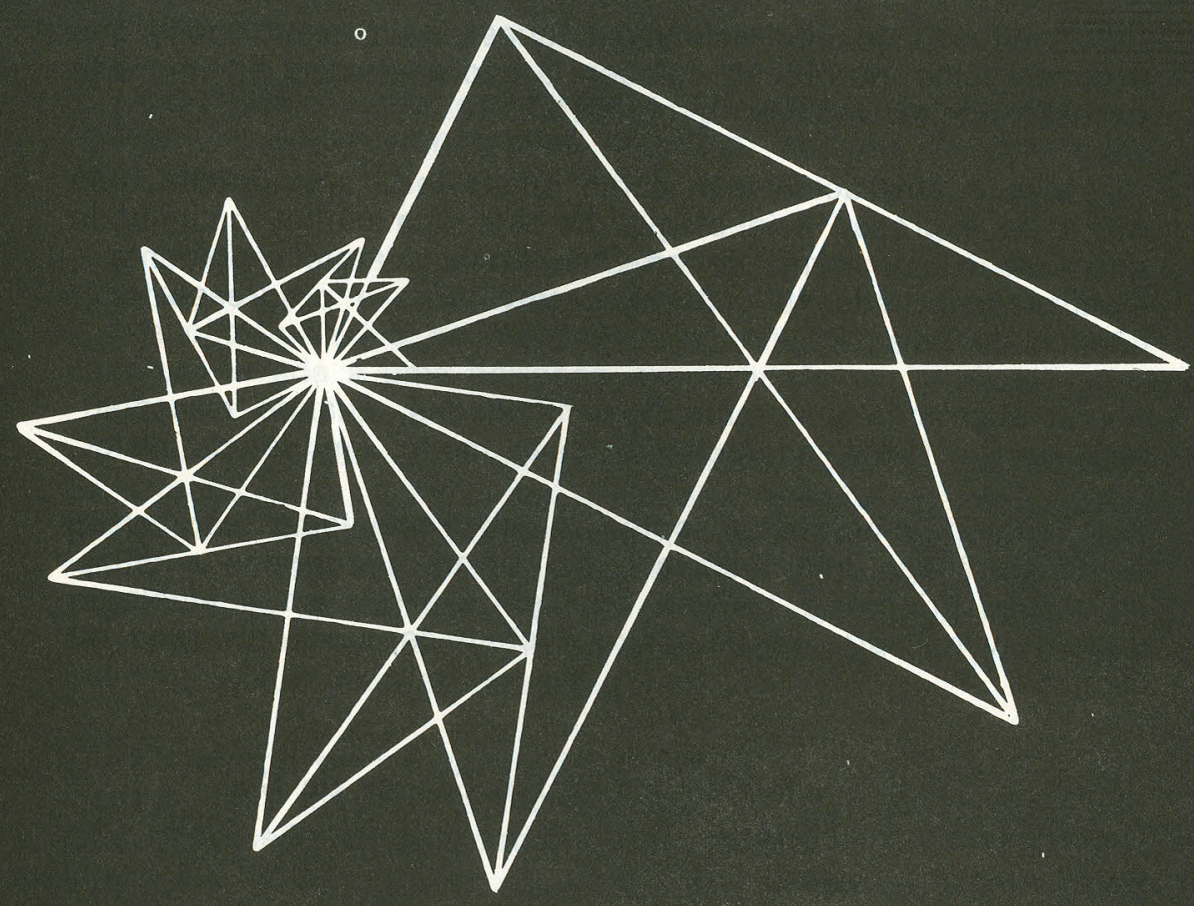




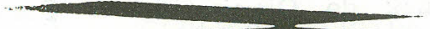
$-\square$ $\longrightarrow$ $\longrightarrow$ $\longrightarrow$

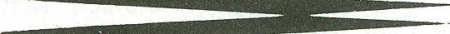
ב$\longrightarrow+\quad-10$

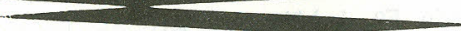
$\longrightarrow$ manch (2)

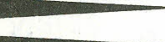

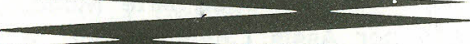
$+$ ב$\longrightarrow$ ב-

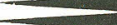
ב

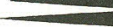

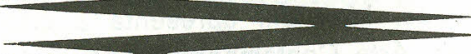

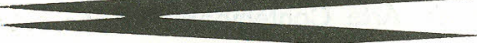
ב-100 $\longrightarrow$ ב-100 $+2$ ing

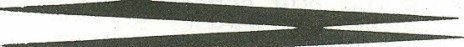

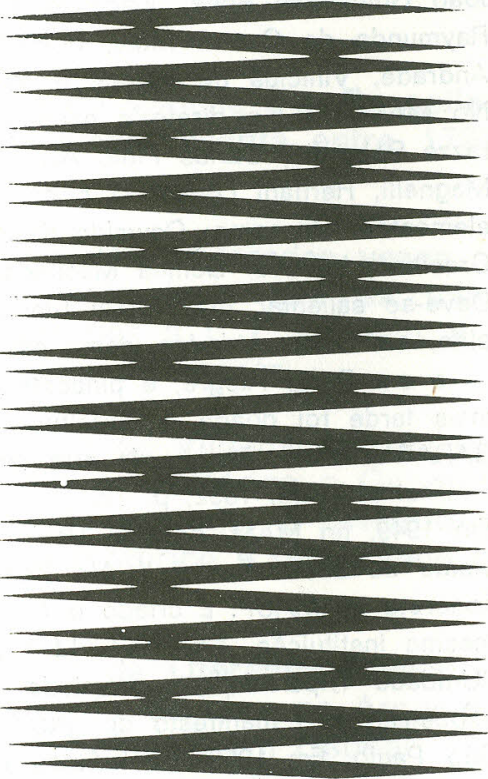




\section{NOTAS}

1 BOSI, Alfredo. "Um testemunho do presente". Nn: Mota, Carlos Guilherme. Ideologia da cultura brasileira, São Paulo, Atica, 1980, p. IV.

2 Usar-se-á o termo elite para designar as diferentes categorias que promovem as manifestações artísticas no eixo-Rio de Janeiro/São Paulo. Por exemplo, no MAM RJ., em 1952, o conselho deliberativo está constituído por industriais, banqueiro, políticos, intelectuais e artistas, entre os quais se destacam: Assis Chateaubriand, Carlos Flexa Ribeiro, Francisco C. Santiago Dantas, Francisco Matarazzo Sobrinho, Gustavo Capanema, João Guimarães Rosa, Juscelino Kubitschek de Oliveira, Lúcio Costa, Raymundo de Castro Maia, Roberto Marinho, Rodrigo Mello Franco de Andrade, Vinicius de Morais e Walter Moreira Sales.

No MAM S.P., a diretoria executiva é constituida por Francisco Matarazzo Sobrinho, Carlos Pinto Alves, Rino Levi, Roberto Paixa Meira, Aldo Magnelli, Hernani Lopes. Já o conselho de administração é formado por elementos tais como: Oswaldo de Andrade Fo, J. Vilanova Artigas, Clóvis Graciano, Lourival Gomes Machado, Sergio Milliet e outros.

Deve-se salientar que foram fundadas outras instituições artísticas pela elite, em outras cidades, como em Recife - o Museu de Arte Moderna - e em Porto Alegre, a pinacotea criada por Assis Chateaubriand, que mais tarde foi doada à Prefeitura dessa cidade.

3 BARATA, Mário, Museu de arie moderna do Rio de Janeiro. Rio de Janeiro, MAM, 1952, p. 12.

4 Em 1949, no MAM, de São Paulo é realizada a exposição "Do figurativismo ao abstracionismo". No ano seguinte, Max Bill apresenta a arte concreta no MASP. É criado o Instituto de Arte Contemporânea por esta mesma instituição. Em 1951, Max Bill tem a sua escultura concreta "Unidade Tripartida" - premiada na $1^{a}$ Bienal. Em 1952, é realizada a exposição e o manifesto do grupo ruptura (de arte concreta) no MAM, São Paulo. Em 1953, os artistas concretos argentinos apresentam seus trabalhos no MAM, Rio de Janeiro. Neste ano, Max Bill faz uma palestra no MAM, Rio de Janeiro e na USP.

5 KLEE, Paul. Théorie de l'art moderne. Paris, Denoel/Gonthier, 1977, p. 34.

6 CORDEIRO, Waldemar. "Ruptura". In: AMARAL, Aracy. Projeio constritivo na arte: 1950-1962. Rio de Janeiro, MAM; São Paulo, Pinacoteca do Estado, 1977, p. 101.

7 - "O objeto". In: AMARiAL, Aracy. Projeto construtivo na arte: 1950-1962. Rio de Janeiro, MAM; São Paulo, Pinacoteca do Estado, 1977. p. 74.

8 GULLAR, Ferreira "Manifesto neoconcreto". In: AMARAL, Aracy, Projeto construtivo na arte: 1950-1962. Rio de Janeiro, MAM; São Paulo, Pinacoteca do Estado, 1977, p. 80-82. 